\title{
Chapter 12 \\ Strengthening the Capacity of Flood-Affected Rural Communities in Padang Terap, State of Kedah, Malaysia
}

\author{
Fera Fizani Ahmad Fizri, Asyirah Abdul Rahim, Suzyrman Sibly, \\ Kanayathu C. Koshy, and Norizan Md Nor
}

\begin{abstract}
The communities in the district of Padang Terap, Kedah, were not used to flood events even though they had been living in the area for generations. Since 2000 , flooding in this area had become a common occurrence as a result of the increased intensity and frequency of rain due to global warming and climate change. Recognizing the need to address the vulnerability and adaptation of the communities and relevant agencies, the Centre for Global Sustainability Studies (CGSS), Universiti Sains Malaysia (USM), carried out a project based on universitycommunity engagement and education for sustainable development (ESD) in this area. The stakeholders involved in this project were from different entities, consisting of experts from USM, residents, local officials, and selected schools in the district. The project identified that the communities of Padang Terap needed counseling for trauma victims, training in handling and maintaining flood-related equipment, accredited flood rescue training, and the establishment of a formal community flood disaster committee consisting of village leaders and the local authorities. In addition, CGSS also addressed public awareness of the dangers of flooding via ESD
\end{abstract}

F.F.A. Fizri $(\square)$

School of Industrial Technology, Universiti Sains Malaysia, 11800 USM, Penang, Malaysia e-mail: fera@usm.my

A.A. Rahim

School of Humanities, Universiti Sains Malaysia, 11800 USM, Penang, Malaysia

e-mail: asyirah@usm.my

S. Sibly • K.C. Koshy

Centre for Global Sustainability Studies, Universiti Sains Malaysia,

11800 USM, Penang, Malaysia

e-mail: suzyrman@usm.my; koshy_k@usm.my

N.M. Nor

School of Humanities, Universiti Sains Malaysia, 11800 USM, Penang, Malaysia

e-mail: norizan_mdnr@yahoo.com 
activities implemented in schools and villages. Close cooperation and positive contributions from academia, local officials, and local communities ensured that the project was successful.

Keywords Capacity building • Community engagement $\bullet$ Disaster preparedness

\subsection{Introduction}

Flooding is a natural disaster caused by climatological factors such as temperature, rainfall distribution, evaporation, wind movements, and the natural terrain (Balek 1983). Fauchereau et al. (2003) and Camerlengo and Somchit (2000) have attributed the change in rainfall distribution to the global warming phenomenon. Flooding can be categorized into river flooding, flash floods, and storm surges. River flooding is caused by heavy and/or continuous rainfall over a period of a few days or weeks in a large area. An important characteristic of this type of flooding is the soil, which becomes saturated, exceeding its capacity to absorb water, and thereby increasing overland flow and water retention (Kron 2002; Berz et al. 2001).

In Malaysia, the flood disasters that occur are due to flash floods, tropical storms, and monsoon storms. On the east coast of peninsular Malaysia, particularly in the states of Terengganu, Kelantan, and Pahang, flooding normally occurs in the rainy season and the frequency of these floods is affected by changes in the monsoon seasons (Chan 1996; Jamaluddin and Sham 1987; Rose and Peter 2001). During the monsoon seasons there is a continuous and increased amount of rainfall, causing the river waters to overflow.

Climate change is seen as a global phenomenon; however, its impacts are localized and long-term. The effects of climate change are evident in the increased occurrence of flooding in the coastal areas of Kedah, Kelantan, Terengganu, Pahang, and Johor. Continuation of this scenario will have a significant impact on the society's culture and economically sensitive sectors as well as on the well-being of those affected.

Among the impacts of floods are pollution; erosion; damage to building structures; loss of property; loss of life; damage to the drainage system; contamination of food and water; disruption of socio-economic activities, including the transportation, telecommunications, and services network; and loss of environmental services resulting from effects such as the degradation of agricultural soil. Flood occurrences in 2006 and 2007 amounted to RM 1.1 billion and RM 776 million in losses, respectively. This amount reflects only the losses incurred by the Malaysian government, and does not take into consideration losses sustained by flood victims and by the local economy.

Those worst affected by the floods are residents who are weak and less well prepared. One of the strategies for flood risk management, therefore, is to make those vulnerable to flood disasters more resilient and better prepared. Efforts need to be focused toward mitigation and enhancing the adaptability or coping capabilities of these residents. 


\subsection{Theoretical Framework}

The Hyogo Framework for Action 2005-2015 document calls on us to promote a strategic and systematic approach to reducing vulnerabilities and susceptibility to hazards. According to the United Nations Office for Disaster Risk Reduction, vulnerability is defined as the conditions determined by physical, social, economic, and environmental factors or processes that increase the susceptibility of a community to the impact of hazards (United Nations International Strategy for Disaster Reduction (UNISDR) 2004a). Viewed in combination with risk, hazards, and capacity, the following equation is derived (United Nations International Strategy for Disaster Reduction (UNISDR) 2004b):

$$
\text { Risk }=\text { Hazards } \times \text { Vulnerability } / \text { Capacity }
$$

Looking at the equation above, it is logical to say that by increasing capacity and reducing vulnerability, risk can be minimized. The Hyogo Framework for Action (United Nations International Strategy for Disaster Reduction (UNISDR) 2007) listed five priorities for action:

1. Ensure that disaster risk reduction is a national and a local priority with a strong institutional basis for implementation

2. Identify, assess and monitor disaster risks and enhance early warning

3. Use knowledge, innovation and education to build a culture of safety and resilience at all levels

4. Reduce the underlying risk factors

5. Strengthen disaster preparedness for effective response at all levels

Using this and the above equation as a basis, capacity building initiatives should be at the forefront of disaster risk management activities.

\subsection{Case Study}

\subsubsection{Study Area}

The area chosen for this study focuses on the district of Padang Terap, Kedah, based on a situational analysis conducted on rain profiling. Padang Terap district was the area most affected during flood disasters from 2000 until 2010. The area covers $135,684.41$ ha and the population size is 72,318, consisting of Malay and MalayThai (DID 2010). Padang Terap district has 12 mukims (sub-districts), and one village head is appointed for each mukim. The study area is shown in Fig. 12.1.

The district of Padang Terap is the second largest district in the state of Kedah. The main economic activities are rubber tapping and farming, and the principal crop grown is paddy. The district's farmers do not, however, plant paddy on a large scale 


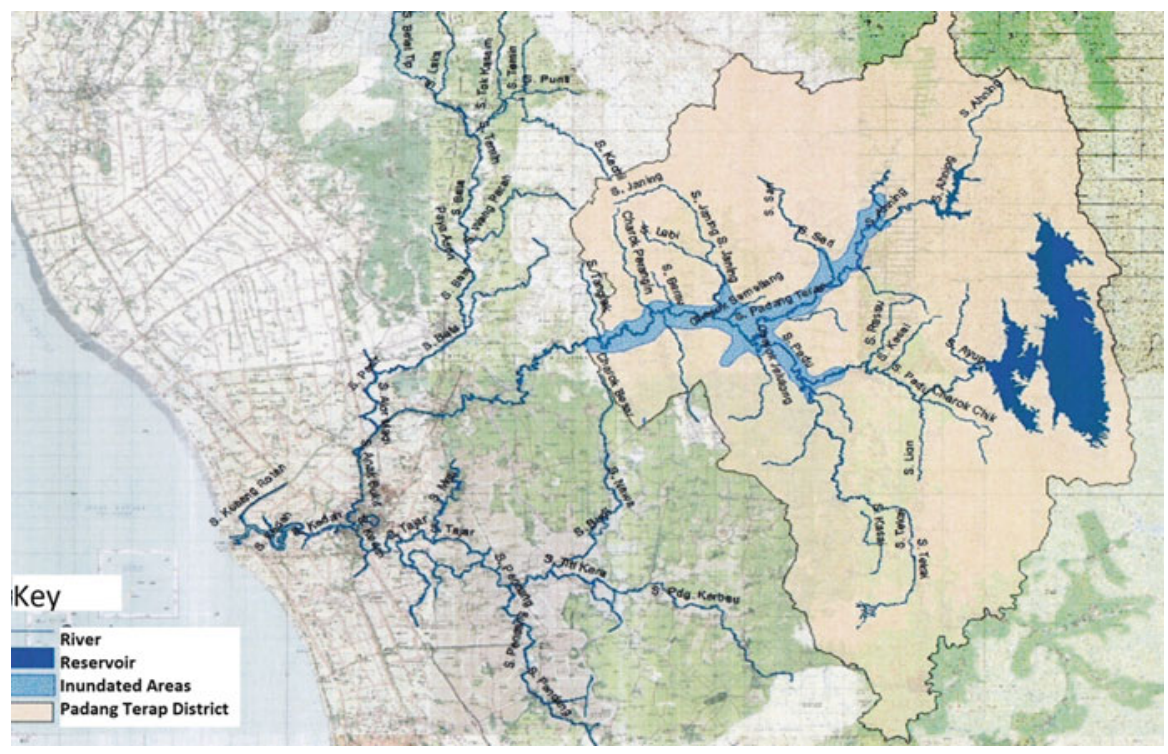

Fig. 12.1 Flooded areas in the Padang Terap District

and are highly dependent on the river and rain water for irrigation. They are very much exposed to the threat of losing their crops and livelihoods if and when a flood occurs in the area.

Flooding occurrences have increased in Padang Terap, happening at least once, and sometimes up to eight times, in a year. The duration of the floods averages about three days, but can last up to fourteen days consecutively.

\subsubsection{Needs Analysis}

In order to curb losses and utilize resources in a more efficient manner, this study focuses on identifying community needs during floods in the district of Padang Terap, Kedah. A survey of the entire population of flood-affected areas was conducted to gain an insight into population demographics and flood related losses. Furthermore, focus group discussions with village heads were held to identify common issues and needs.

\subsubsection{Survey}

A survey was conducted to assess the flood victims' needs during flood disasters, as well as to develop a valid and verified set of baseline data. The sampling method 
Table 12.1 Respondents' needs during floods

\begin{tabular}{lc}
\hline Needs & $\begin{array}{c}\text { Number of } \\
\text { respondents }\end{array}$ \\
\hline Assistance to move and lift belongings & 146 \\
Food supplies & 96 \\
Access to communication & 88 \\
Rescue assistance & 45 \\
Assistance in moving to a safe place & 31 \\
Access to electricity, water, and other utilities & 17 \\
Quicker/faster flood assistance & 14 \\
Assistance with watching over assets & 10 \\
Medical care & 7 \\
\hline
\end{tabular}

Table 12.2 Respondents' needs after floods

\begin{tabular}{lc}
\hline Needs & Number of respondents \\
\hline Assistance to tidy and clean up & 579 \\
Assistance to replace damaged & 33 \\
$\quad$ belongings & \\
Medical care & 8 \\
Food supplies & 8 \\
Monetary assistance & 3 \\
\hline
\end{tabular}

chosen for this study was purposive sampling, whereby the respondents selected were those directly involved in paddy farming, vegetable farming, and other types of agricultural activity.

Based on the existing data from the district office, 62 kampungs (villages) under 11 mukims were identified as flood-affected areas in the Padang Terap district. Once the kampungs and mukims associated with floods were identified, specific flood areas were located with help from ketua kampung (village leaders). The survey was then carried out in the specifically identified flood areas.

The survey was distributed to 683 flood victims to obtain their demographic information, to identify vulnerable groups and affected areas, and to identify the needs of the victims before, during, and after a flood occurs. The data analysis was conducted using SPSS Software version 17.

The total number of flood victims in the 11 mukims was 683. The mukims of Belimbing Kiri and Belimbing Kanan had the highest number of flood victims at 179 and 172, respectively, accounting for $51 \%$ of the total flood victims in Padang Terap.

The educational levels of the flood victims were found to be quite low. The majority of respondents (538 respondents, $79 \%$ ) had experienced primary and secondary education only, while 99 respondents $(14.5 \%)$ had no formal education.

As shown in Table 12.1, during floods the majority of respondents needed one or more of the following: (1) assistance with moving and lifting belongings, (2) food supplies, (3) access to means of communication, (4) rescue assistance, or (5) assistance in moving to a safe place. After flooding, 579 respondents required assistance to tidy up and clean their houses and equipment such as high-pressure jet sprays (Table 12.2). 
Table 12.3 Respondents' actions before, during, and after floods

\begin{tabular}{lr}
\hline & Number of respondents \\
\hline Before floods & \\
Did not save contingency money & 626 \\
Elevated belongings & 145 \\
Safeguarded important documents & 101 \\
Moved vehicles to higher ground & 97 \\
Bought food supplies & 84 \\
Saved contingency money & 57 \\
Moved to a safer place & 19 \\
Built higher/elevated home & 3 \\
During floods & \\
Moved to flood shelter & 228 \\
Moved belongings to a safer place & 184 \\
Contacted relevant authorities & 73 \\
After floods & \\
Cleaned mud from house & 440 \\
Attended medical checkup & 127 \\
Disinfected belongings, etc. & 104 \\
Sought counseling & 15 \\
\hline
\end{tabular}

When asked about their preparations before floods occur, only a handful of the respondents had made monetary preparations for flooding (57 respondents, $8 \%$ ). Most of the respondents did not make any monetary preparations, and despite floods being a common occurrence since the year 2000 , only three respondents $(0.4 \%)$ had adapted by building elevated homes (Table 12.3).

Most of the respondents appeared to be aware of what needs to be done during flooding, with 228 (33\%) stating that they would move to flood shelters, and 184 (27\%) saying that they would move their belongings to a safer place (Table 12.3).

After floods subsided, most of the respondents (440, $64 \%$ ) concentrated their efforts on cleaning the flood residue from their houses. Another 104 respondents (15\%) started making arrangements to disinfect their houses, and 127 respondents (18\%) went for a post-flood medical checkup (Table 12.3).

\subsubsection{Focus Group Discussions}

A qualitative approach, the Focus Group Discussion (FGD), was used to identify problems and needs from the flood victims' perspective. This method was used to obtain a better understanding of specific issues, which is vital as it can lead to implementation of appropriate and effective solutions before, during, and after floods. The main stakeholders involved in the FGD were representatives from the Majlis Ketua Kampung (Village Head Council) of Padang Terap and the Jawatankuasa Kemajuan \& Keselamatan Kampung (Village Development \& Security Committee). 
Since there are two different village-level administrative committees representing the federal government and state government, respectively, two separate FGD groups were convened. One catered to the federal government village committee, the other to the state government village committee. A total of 32 representatives from 29 kampungs (villages) attended the FGD sessions. Of the 32 representatives, 18 were representatives of the state committee while the remaining 14 were representatives of the federal government committee.

The FGD primarily focused on the problems faced by both the federal and state representative committees related to flood occurrences. The purpose of this exercise was to provide a basic understanding of the major issues faced by the authorities in particular before, during, and after a flood occurs. Among the major issues raised during the FGD were:

1. Dissemination of information on rising flood water levels to flood affected communities was slow and inefficient.

2. Victims in flood shelters did not receive food supplies on time due to delays in the supplies reaching the shelters.

3. There were insufficient rescue boats available for mobilization during flooding.

4. Other equipment, such as high-pressure water jet sprays to clean houses after flooding, tents for constructing emergency shelters, and portable gas-powered generators to provide electricity were lacking, despite being urgently required to prepare for future flood occurrences.

\subsubsection{Capacity Building Activities}

Several measures were identified to strengthen capacity within the local community and Padang Terap's local authority. Bearing in mind that children and the elderly were the most vulnerable, a Bahaya Ayaq Bah awareness campaign was conducted in six schools within the Padang Terap district. Bahaya Ayaq Bah is a phrase in the local dialect meaning "The Dangers of Flooding." The schools comprised Sekolah Kebangsaan Toh Puan Syarifah Hanafiah, Sekolah Kebangsaan Kurong Hitam, Sekolah Kebangsaan Padang Sanai, Sekolah Kebangsaan Kubang Palas, Sekolah Kebangsaan Kuala Nerang, and Sekolah Kebangsaan Seri Bakti. These schools are among those that, in the event of a flood, would be either inundated, surrounded by flood waters, or turned into disaster relief centers. In addition to being educated on the dangers of flooding, pupils were also exposed to what needs to be done before, during, and after a flood occurs. The campaign comprised activities in the form of crossword puzzles, quizzes, and short talks on flooding, as well as an introduction to the $3 \mathrm{~S}$ concept.

The 3S concept (Sebelum, Semasa, Selepas) was coined from the local terminology for "before," "during," and "after" flood occurrence. Information relating to the three stages was disseminated to the students, advising them to ascertain if their 
homes were vulnerable to flood, to evacuate their homes once the flood warning was issued by the authorities, and to ensure the whereabouts of each family member during the evacuation process. In addition, the students were reminded to be careful about personal protection, for example by wearing gloves during the cleaning process, and to clean and disinfect furniture and appliances thoroughly to avoid waterborne or water-related diseases.

Coping capacities are defined as the ability of a society or group, organization, or system to use its own resources to address and manage emergencies, disasters, or adverse conditions that could lead to a harmful process caused by a hazard event (UNISDR 2009). To increase the coping capacities of the local community, residents were introduced to the concept of a "flood kit." According to the survey conducted, the local community experienced difficulty with evacuating or being rescued. Due to the high number of victims and insufficient resources, evacuation was subject to delays. In order for the locals to cope with the situation, they were encouraged to prepare a flood kit. This would consist of basic first aid items and toiletries, a flashlight, a bottle of water, food items such as instant noodles and biscuits, and a plastic folder to hold important documents. The flashlight would be useful during the night, especially if the electricity had been cut off, and the food items would tide the family over until help arrived. Every household was encouraged to prepare a flood kit for each family member.

In addition to preparing families for disaster, training was also given to the local community on handling and maintenance of rescue boats. Incorporating rescue measures and procedures, and proper usage of life vests and floatation devices, the training was conducted by the Public Defense Department, the Fire and Rescue Department, the Police Department, and the Muda Agriculture Development Authority (MADA).

\subsection{Future Research and Recommendations}

This project covered only certain issues identified in the survey and raised during the FGD. Other issues such as insufficient communication and long-term adaptation strategies will need to be addressed in future. Implementation of an early warning system or a flood alert is also important. Warning systems will need to be efficient to enable proper preparation for evacuation. These systems have to run without electricity and reach even the most secluded homes.

Acknowledgment We would also like to express our utmost gratitude to this project's research officer, Mr. Mohd Zulhafiz Said, and his assistants employed under the USM APEX Delivering Excellence grant, for collecting data for this project.

Open Access This article is distributed under the terms of the Creative Commons Attribution Noncommercial License which permits any noncommercial use, distribution, and reproduction in any medium, provided the original author(s) and source are credited. 


\section{References}

Balek J (1983) Hydrology and water resources in tropical regions. Dev Water Sci 18:216-235

Berz G, Kron W, Loster T, Rauch E, Schimetschek J, Schmieder J, Siebert A, Smolka A, Wirtz A (2001) World map of natural hazards-a global view of the distribution and intensity of significant exposures. Nat Hazards 23:443-465

Camerlengo AL, Somchit N (2000) Monthly and annual rainfall variability in peninsular Malaysia. Pertanika J Sci Technol 8(1):73-83

Chan NW (1996) Vulnerability of urban areas to floods. Star 1996:4-6. Climate Change Research, UK

Department of Irrigation and Drainage (2010) Kedah flood report. Department of Irrigation and Drainage, Kedah

Fauchereau NS, Trzaska MR, Richard Y (2003) Rainfall variability and changes in Southern Africa during the 20th century in the global warming context. Nat Hazards 29:139-154

Jamaluddin J, Sham S (1987) Development process, soil erosion and flashfloods in the Kelang Valley Region, Peninsular Malaysia: a general consideration. Arch Hydrobiol Beih 28: 399-405

Kron W (2002) Flood risk = hazard × exposure × vulnerability. In: Wu B, Wang ZY, Wang G, Huang GGH, Fang H, Huang J (eds) Flood defense. Science Press, New York

Rose S, Peter EN (2001) Effect of urbanization on stream flow in the Atlanta area (Georgia, USA): a comparative hydrological approach. Hydrol Process 15(8):1441-1457

United Nations International Strategy for Disaster Reduction (UNISDR) (2004a) Living with risk: a global review of disaster reduction initiatives. Preliminary version. Inter-Agency Secretariat of the International Strategy for Disaster Reduction, Geneva, p 382 http://www.unisdr.org/eng/ about_isdr/bd-lwr-2004-eng.htm

United Nations International Strategy for Disaster Reduction (UNISDR) (2004b) Disaster risk reduction tools and methods for climate change adaptation. UNISDR, Geneva

United Nations International Strategy for Disaster Reduction (UNISDR) (2007) Hyogo framework for action 2005-2015: building the resilience of nations and communities to disasters. United Nations, Geneva

United Nations International Strategy for Disaster Reduction (UNISDR) (2009) Global assessment report on disaster risk reduction. Risk and poverty in a changing climate - invest today for a safer tomorrow. United Nations, Geneva 